\title{
EXPRESSION OF CYTOKERATIN 7, 20, 14 IN UROTHELIAL CARCINOMA AND SQUAMOUS CELL CARCINOMA OF THE EGYPRIAN URINARY BLADDER CANCER By \\ OLFAT HAMMAM ${ }^{* 1}$, MOHAMED WISHAHI ${ }^{2}$, HEBA KHALIL ${ }^{1}$, HOSSAM EL GANZOURI ${ }^{2}$, MOHAMED BADAWY ${ }^{2}$, AMR ELKHOULY ${ }^{2}$, KHALED ELESAILY ${ }^{2}$ Departments of Pathology ${ }^{1}$ and Urology ${ }^{2}$, Theodor Bilharz Research Institute, Imbaba P.O. Box 30, Giza, Egypt \\ ${ }^{*}$ Corresponding author: E-mail (totoali1@hotmail.com)
}

\begin{abstract}
This study estimated the expression of CK-7, CK14, and CK-20 protein in human bladder carcinoma, urothelial carcinoma (UC) in comparison to squamous cell carcinoma (SCC) and to show its possible correlation to clinicopathologic parameters (grade and stage and bilharziasis), and investigate whether cytokeratin 14 immunostaining may be useful to detect early squamous metaplasia in bladder biopsies and in association with UC. We evaluated the bladder tissues of 200 patients with bladder carcinoma, 150 patients had UC, and 50 patients had SCC. Imunohistochemical technique was used for detection of CK7, CK14 and CK20 monoclonal antibodies. The mean age of the patients was 55 years (range51- 70 years). The UC were classified according to grades into grade I, II and III in 20, 40 and 90 cases, respectively. Stages of UC were: Ta in 10, T1 in 60 and 90 patients with muscle-invasive T2-3. In UC cases $105 / 150(70 \%)$ were positive for over expression of CK20. In the same group of UC 120/150 (80) were positive for over expression of CK7. Negative expression was found in SCC cases. A High grades of the UC were associated with decrease expression of CK 20, there were $20(100 \%)$ in GI, $35(87.5 \%)$ in GII, $50(68.6 \%)$ in GIII $(\mathrm{P}<0.01)$, and an increase expression of CK7 4 (20\%) in GI, $26(65 \%)$ in GII, 90(100\%) in GIII (P $<0.01)$. CK20 expression decreased as the tumor stages increased, it was $15(100 \%)$ in Ta, $50(83.3 \%)$ in T1, 40 $(50 \%)$ in $\mathrm{T} 2-3(\mathrm{P}<0.01)$, while CK7 showed increase expression in 2 cases with Ta tumor $(20 \%), 38(47.5 \%)$ in $\mathrm{T} 1,80(100 \%)$ in $\mathrm{T} 2-\mathrm{T} 3(\mathrm{P}<0.01)$. The present study confirmed that CK14 is expressed in SCC and in UC with squamous differentiation.
\end{abstract}

Keywords: Egypt, Carcinoma bladder, Cytokeratin 7, Cytokeratin14, cytokeratin 20, immunohistochemistry, Schistosomiasis.

\section{Introduction}

Urinary schistosomiasis is caused by infection with Schistosoma haematobium and greater research effort and focus are needed to improve understanding of this neglected tropical disease (Rollinson 2009). Carcinoma of the bladder is the most common oncological problem in Egypt. In 1981, the National Cancer Institute published evidence that bladder cancer constituted $30.3 \%$ of all cancers: $40 \%$ of male cancers, and $14.3 \%$ of female cancers. However, a lower overall frequency of $10.2 \%$ was reported by other Egyptian general hospitals (El-Mawla et al, 2001). Carcinoma of the urinary bladder oc- curs at high frequency in Egypt where schistosomiasis is endemic (El Bolkainy et al, 2001). The current lack of genome and transcriptome information for the Schistosoma haemtobium is directly hindering further targeted research and must be quickly rectified (Rollinson, 2009). Cytogenetic changes of bladder cancer include a stepwise genetic process involving a succession of genes and resulting in abnormal cellular biology, ranging from an increased proliferative capacity of the affected cells to malignant transformation and ultimate assumption of invasive and/or metastatic capacity (Sandberg and Berger, 1994). 
Cytokeratins are proteins of keratin containing intermediate filaments found in the intracytoplasmic cytoskeleton of epithelial tissue. Cytokeratin 20 (CK20), a low molecular weight cytokeratin, is specifically $e_{x-}$ pressed in the superficial and in some of the intermediate cells of the normal urothelium, gastrointestinal mucosa and Merkel cells, it is also expressed in TCC but is generally absent in squamous tumors of multiple tissue types, including squamous cell carcinoma of the bladder (Moll et al, 1992; Sou et $a l, 1993)$. Cytokeratin 20 is detected in some urothelial carcinomas and is associated with recurrence in the bladder (Harnden and Southgate, 1997). Cytokeratin 7 (CK7) is another intermediate filament that is found in urothelial neoplasia of the urinary bladder. Immunohistochemical staining of $\mathrm{CK} 7$ and CK20 proved to be a helpful diagnostic aid in differentiating the origin of carcinomas, including urothelial carcinoma of urinary bladder (Wang et al, 1995; Chu et al, 2000). The subset of cytokeratin's which an epithelial cell expresses depends mainly on the type of epithelium, the moment in the course of terminal differentiation and the stage of development. Thus this specific cytokeratin fingerprint allows the classification of all epithelia upon their cytokeratin expression profile. Furthermore, this applies also to the malignant counterparts of the epithelia (carcinomas), as the cytokeratin profile tends to remain constant when an epithelium undergoes malignant transformation. The main clinical implication is that the study of the cytokeratin profile by immunohistochemistry techniques is a tool of immense value widely used for tumor diagnosis (Walid et al, 2009) and characterization in surgical pathology (Moll et al, 1992).

In vitro studies have shown that squamous differentiation of human urothelial cells (induced by retinoid deficiency in the growth medium) is accompanied by de novo expression of cytokeratin 14 (Harnden and Southgate, 1994). In a clinical setting, Harnden and Southgate (1994) have suggested that cytokeratin 14 expression is a sensitive early marker of a switch to a squamous phenotype within urothelial tumours. These authors identified focal positive staining for cytokeratin 14 in $47 \%$ of transitional cell carcinomas of the bladder, which showed no morphological evidence of squamous differentiation on routine H\&E staining (Harnden and Southgate, 1997). Cytokeratin 14 is a marker of nonkeratinising (stratified and nonstratified) squamous epithelium (Chu and Weiss, 2002).

This study was conducted to estimate the over expression of CK-7, CK14, and CK-20 protein in human bladder carcinoma urothelial carcinoma (UC) in comparison to squamous cell carcinoma(SCC) and to show its possible correlation to clinico-pathologic parameters (grade and stage bilharziasis), and investigate whether cytokeratin $14 \mathrm{im}$ munostaining may be useful to detect early squamous metaplasia in bladder biopsies.

\section{Subjects, Material and Methods}

The enrolled patients were 200 admitted to the Urology Department at the Theodor Bilharz Research Institute (TBRI) Hospital with bladder lesions. One hundred and twenty (120/62) were associated with schistosomiasis. Schistosomiasis haematobium was diagnosed by the detection of Schistosoma ova in urine by Nucleopore technique (ElBaz et al, 2003) and tissue samples or detecting schistosomal antibodies in serum using the commercial available ELISA, adopting the technique of El Missiry et al. (2000).

The 200 patients consisted of 175 males and 25 females (aged mean 58 years (range 51-70 years). Twenty patients subjected to prostatectomy served as normal controls after obtaining their consent. Bladder biopsies were taken during prostatectomy from the trigon area. Tumor specimens were obtained by cystoscopy (transurethral resection biopsies (TUR) and from cystectomy specimens. Only biopsies containing muscle tissue were included, so that muscle invasion by the tumor could be assessed. The study protocol was approved by the institutional committee 
for the protection of human subjects and conformed to the guidelines of the 1975 Declaration of Helsinki. The patients were subjected to full clinical examination, routine laboratory investigations, complete urine analysis, abdominal and pelvic ultrasonography, general and abdominal examination, digital rectal examination (DRE), bimanual examination under anesthesia, plain X-ray of the urinary tract, intravenous urography (IVU), cystoscopy and TUR biopsies were taken from apparent growths.

Histopathological study: Tissues were fixed in $10 \%$ buffered formalin, paraffin-embedded and processed to TMA. Hematoxylin and Eosin stains were used to evaluate all bladder lesions and to assess carcinoma grade and stage (Eble et al, 2004). Samples were classified into three groups: G1: nonschistosomal-associated urothelial carcinoma (80 cases); G2: schistosomal-associated urothelial carcinoma (70 cases); G3: schistosomal-associated squamous cell carcinoma (50 cases).

Tissue Array Construction: Tissue microarray (TMA) was constructed as previously described (Hoos et al, 2001), TMA was assembled using a commercially available manual tissue puncher /arrayer (Beecher Instruments, Silver Spring, MD). Fresh sections were cut from the donor block and stained with hematoxylin-eosin (H\&E), these slides were used to guide the samplings from morphologically representative regions of the tissues. A tissue array instrument was used to create holes in a recipient paraffin block and to acquire tissue cores from the donor block by a thin walled needle with an inner diameter of $2 \mathrm{~mm}$, at a distance of $1 \mathrm{~mm}$ between each core, held in an X-Y precision guide. The cylindrical samples were retrieved from the selected regions in the donors and extruded directly into the recipient blocks with defined array coordinates. As a control, tissue cores taken from paraffin blocks of non-neoplastic mucosa of 20 patients undergoing surgery for nonmalignant conditions were additionally ar- rayed on each block. After the construction of the array block, multiple 4- $\mu \mathrm{m}$ thick sections were cut with a microtome using an adhesive coated tape sectioning system (Instrumedics, Hackensack, NJ).

Immunohistochemical procedure: Tissue microarray bladder sections $(4 \mu)$ were collected from formalin-fixed, paraffinblocks on microscopic slides coated with 3amino propyl triethoxy silane (Sigma). The using of the standard streptavidin-biotin peroxidase complex method (APC) method, was according to Hsu et al. (1981), following deparaffinization and rehydration. Endogenous peroxidase activity was blocked using 3\% solution of hydrogen peroxide in methanol for 30 minutes at room temperature then antigen retrieval was performed by microwaving in $10 \mathrm{mM}$ citrate buffer, $\mathrm{pH}$ 6.0 for 15 minutes. Non-specific antibody binding was prevented by pre-incubation with $100 \mathrm{~mL}$ blocking serum for $30 \mathrm{~min}$ at room temperature.

Sections were incubated overnight with the antihuman antibodies: for cytokeratin 7 , cytokeratin 14 and cytokeratin 20 monoclonal antibodies (Dako, Glosturp, Denmark) at the optimal working dilution of $1: 100,1$ : 200, 1:200, respectively. After the thorough washing in buffer, we used substrate chromogen mixture (A biotinylated secondary anti-immunoglobulin (IgG) LSAB ${ }^{\circledR}$ System (k0679), a preformed Streptavidin biotinylated horseradish peroxidase complex and the chromogen used were 3-3' diaminobenzidine tetrahydro-chloride (D.A.B.) (DAKO, Denmark) and sections were counterstained with Mayer's hematoxylin before mounting. Positive control was done using colon cancer. Negative control slides included a blank control and omission of primary antibody. Positive and negative controls were stained in the same settings (battery) of stain to standardize the present technique.

Sections with less than $50 \%$ of the original tissue remaining on the slides after processing were excluded and not scored. Evaluation of the immunohistochemical staining 
was performed independently by two authors without knowledge of the clinicopathological information. Cytokeratin 7, cytokeratin 14 and cytokeratin 20 immunoreactivities were observed as cytoplasmic brownish coloration of the cells, with scoring as: tumors were scored by two independent observers based on the percentage of tumor cells staining positive within each tumor. Tumors were scored as positive for CK20 when more than $30 \%$ of the cells expressed these proteins (McKenney et al, 2001).

Statistical analysis: The SPSS software version 11 was used for data management and analysis. Quantitative data were presented as mean + SD. Qualitative data were presented as frequencies and percentages and the chi-square was used. To study the relationship between two variables Spearman's correlation coefficient was calculated. All tests were two tailed and considered statistically significant when ( $p$ value $<0.05$ ).

\section{Results}

CK20 staining was positive in $140(70 \%)$ of 200 specimens with UC histology, but none of the 70 SCC specimens exhibited this protein $(\mathrm{P}<0.001)$. The UC were classified according to grades into grade I, II \& III in 20, 40 and 90 cases respectively and according to stages into Ta in 10, T1 in 60 and T23 in 90 .

From the 150 cases of TCC, $105(70 \%)$, $120(80 \%)$ of patients were positive for over expression of CK 20 and CK 7 and no expression were found in cases SCC.

A High histological grades of the UC were associated with decrease expression of CK20, there were $20(100 \%)$ in GI, 35 $(87.5 \%)$ in GII, 50 (68.6) in GIII $(\mathrm{P}<0.01)$ and increase expression of CK7 $4(20 \%)$ in GI, $26(65 \%)$ in GII, 90(100\%) in GIII (P $<0.01)$.

The cytokeratin 20 expression decreased as the tumor stages increased, it was 15 $(100 \%)$ in Ta, $50(83.3 \%)$ in T1, $40(50 \%)$ in T2-3 ( $\mathrm{P}<0.01)$, and CK7 showed increase expression in $2(20 \%)$ in $\mathrm{Ta}, 38(47.5 \%)$ in $\mathrm{T} 1,80(100 \%)$ in $\mathrm{T} 2-3(\mathrm{P}<0.01)$ (Tab.1; Fig.1. A-D).

All the pure squamous cell carcinomas were positive for the CK14 and negative for the CK20, Immunocytochemistry for CK14 further detected clusters of cells with a squamous phenotype in 87 cases $(58 \%)$ of the transitional cell carcinomas within morphological areas of squamous differentiation and with no morphological evidence of squamous differentiation.

Expression of CK14 was expressed in all layers of the urothelium in squamous cell carcinomacases, unlike in normal squamous epithelium where CK14 expression was confined to the basal layer (Fig.1D). The percentage positivity and expression patterns of CK 20 and CK 7 were more or less similar for patients with or without bilharziasis and no difference between both groups.

\section{Discussion}

Cytokeratin 20 is the most recently identified type I keratin protein of $46 \mathrm{KD}$, which shows a limited pattern of expression in normal tissues (Moll et al, 1999). The expression of CK20 in urothelium was restricted to superficial umbrella cells even in the presence of severe inflammation. Only malignancy induced alteration in CK20 expression pattern. The pattern of CK20 immunohistochemical staining is a useful adjunct morphology in the diagnosis of urothelial dysplasia, since only malignant cells would show CK20 immunostaining (Alsheikh et al, 2001).

In the presented study, there was diffuse cytoplasmic staining of CK20 in most of the UC specimens, these results agreed with (McKenney et al, 2001) who found 21(75\%) stained positive for CK20 in TCC. Also our result agrees with (Harnden et al, 1996). While CK20 was not expressed in SCC these finding agreed with Jason et al. (2003), so absence of CK20 in squamous metaplastic lesions implies that this biomarker is not expressed when urothelial cells are trans- 
formed to the squamous phenotype (LopezBeltran et al, 2004). According to grades of UC CK20 expression decreased with increasing grades of tumors these results agree with (Harnden et al, 3003). Regarding the stages of UC, the CK20 expression decreased with the increasing stages of tumors. These results agreed with those of McKenney et al. (2001). The expression of this tumor marker appear to be dependent on the tumor type, grades and stages of tumor, the expression of CK20 in superficial TCC lesions has been associated with lower rates of tumor recurrence (Moll et al, 1990).

The present study evaluated the expression of CK20 and CK7 in bladder cancers from patients with or without bilharziasis to determine whether transitional and squamous cell carcinomas in this population display distinct patterns of expression of these proteins. The observed diffuse cytoplasmic staining of CK20 was in most of the UC specimens; but withut difference between groups associated with or without bilharzisis and these was in agreement with the findings of El-Messery et al.(2008).

The CK14 was expressed in all SCC and in UC within morphological areas of squamous differentiation, Dual expression of these markers may be useful in confirming the primary nature of a poorly squamous differentiated carcinoma, On the other hand, the demonstration of CK14 but not CK20 positivity should direct investigations towards the usual sites of primary squamous cell carcinomas.

The cytokeratin 14 was expressed in 58\% of urothelial carcinoma within morphological areas of squamous differentiation and with or without morphological evidence of squamous differentiation. Therefore, CK14 expression may be a sensitive marker within urothelial tumors of a switch towards a squamous phenotype. Investigation of $\mathrm{CK}$ profiles rather than reliance on morphology alone may be of value in clinical studies as it has been shown that the chemotherapeutic agents could modify CKs, and that the drug resistance phenotype in vitro correlates with the expression of specific CK subtypes.

\section{Conclusion}

The outcome results showed that application of immunohistochemical method to detect CK14 in the bladder biopsy specimens would diagnose the presence of squamous differentiation and associated SCC in the urothelial tumors.

This study demonstrated that the histologic phenotypes of squamous and urothelial tumors are reflected in their expression of this protein and is modified further as tumors progress in grades and stages, CK20 appears to be a useful marker for urothelial carcinoma cells.

This is a preliminary assessment of data; further correlation with clinical course regarding recurrence, metastasis, and survival are ongoing and will be published elsewhere soon.

\section{References}

Alsheikh, A, Mohmedali, Z, Jones, E, Masterson, J, Gilks, CB, 2001: Comparison of the WHO /ISUP Classification and CK20 expression in predicting the behavior of low-grade papillary urothelial tumors. Mod. Pathol. 14:26772.

Chu, PG, Weiss, LM, 2002: Keratin expression in human tissues and neoplasms. Histopathology 40: 403-39.

Chu, P, Wu, E, Weiss, LM, 2000: Cytokeratin 7 and cytokeratin 20 expression in epithelial neoplasms: a survey of 435 cases. Mod. Pathol. 13:962-72.

Eble, JN, Sauter, G, Epstein, JI, Sesterhenn, I, 2004: World Health Organization classification of tumors: In: Pathology and Genetics of Tumors of the Urinary System and Male Genital Organs. Lyon: IARC Press.

EI Baz, MA, Morsy, TA, EI Bandary, MM, Motawea, SM, 2003: Clinical and parasitological studies on the efficacy of mirazid in treatment of schistosomiasis haematobium in Tatoon, Etsa Center, El Fayoum Governorate. J. Egypt. Soc. Parasitol. 33, 3:761-76.

El Bolkainy, MN, Mokhtar, NM, Ghoneim, M A, 1981: The impact of schistosomiasis on the 
pathology of bladder carcinoma. Cancer 48: 2643-8.

El-Mawla, NG, El-Bolkainy, MN, Khaled, HM, 2001: Bladder cancer in Africa: update. Semin. Oncol. 28: 168-7.

El-Messery, S, Saied, E, Gawish, K, 2008: Expression of CD44 Protein and Cytokeratin 20 in Non Bilharzial and Bilharzial Bladder Carcinoma. Tanta Med. Sci. J. 3, 4:198-214

El Missiry, AG, el Serougi, AO, Salama MM et al, 1990: Evaluation of dot ELISA technique in the serodiagnosis of schistosomiasis in Egypt. J. Egypt. Soc. Parasitol. 29, 1:34

Harnden, P, Southgate, J, 1997: Cytokeratin 14 as a marker of squamous differentiation in transitional cell carcinomas. J. Clin. Pathol. 50: 1032-3.

Harnden, P, Eardley I, Joyce, AD, Southgate J, 1996: Cytokeratin 20 as an objective marker of urothelial dysplasia. Br. J. Urol. 78:870-5.

Hoos, A, Urist, MJ, Stojadinovic, A, Mastorides, S, Dudas, ME, et al, 2001: Validation of tissue microarrays for immunohistochemical profiling of cancer specimens using the example of human fibroblastic tumors. Am. J. Pathol. 158:1245-51.

Hsu, SM, Raine, L, 1981: Protein A, Avidin and biotin in immunohistochemistry. J. Histochem. Cytochem. 29:1349-53.

Jason, R, Gee, MD, Roselina, G, Montoyaa, Hussein, M, Khaled, Anita, L, et al, 2003: $\mathrm{Cy}-$ tokeratin 20, AN43, PGDH, and COX-2 expression in transitiona and squamous cell carcinoma of the bladder. Urologic Oncology: Semin. Orig. Investigat. 21:266-70.

Lopez-Beltran, A, Luque, RJ, Alvarez-Kindelan, J, et al, 2004: Prognostic factors in survival of patients with stage Ta and T1 bladder urothelial tumors: the role of G1-S modulators (P53, P21Waf1, P27Kip1, cyclin D1, and cyclin D3), proliferation index, and clinico-pathologic parameters. Am. J. Clin. Pathol. 122:444-52.

McKenney, JK, Desai, S, Cohen, C, Amin, M B, 2001: Discriminatory immunehisto-chemical staining of urothelial carcinoma in situ and nonneoplastic urothelium an analysis of cytokeratin 20, P53, and CD 44 antigens. Am. J. Surg. Pathol. 25:1074-8.

Moll, R, Lowe, A, Laufer, J, Franke, WW, 1992: Cytokeratin 20 in human carcinomas. A new histodiagnostic marker detected by monoclonal antibodies. Am. J. Pathol. 140:427-47.

Moll, R, Schiller, DL, Franke, WW, 1990: Identification of protein IT of the intestinal cytoskeleton as a novel type patterns. J Cell J Cell Biol. 111, 2:567-80.

Rollinson D, 2009: A wake up call for urinary schistosomiasis: reconciling research effort with public health importance. Parasitology 136: 1593-610.

Sandberg, AA, Berger, CS, 1994: Review of chromosome studies in urological tumors. IICytogenetic and molecular genetics of bladder cancer. J. Urol. 151:545-60.

Southgate, J, Hutton, KA, Thomas, DF, Trejdosiewicz LK, 1994: Normal human urothelial cells in vitro: proliferation and induction of stratification. Lab. Invest. 71:583-94.

Suo, Z, Holm, R, Nesland, JM. 1993: Squamous cell carcinomas. An immunohistochemical study of cytokeratins and involucrin in primary and metastatic tumours. Histopathology 23:4554.

Wang, NP, Zee, S, Zarbo, RJ, et al, 1995: Coordinate expression of cytokeratin 7 and 20 defines unique subsets of carcinomas. Appl. Immunohistochem. 51:219-23.

Walid, MS, Osborne, TJ, Robinson, JS, 2009: Primary brain sarcoma or metastatic carcinoma? Indian J. Cancer 46, 2:174-5. 
Table 1: Tissue expression of cytokeratin 7, cytokeratin 14 and cytokeratin 20 in relation to prognostic factors.

\begin{tabular}{|c|c|c|c|c|}
\hline Progostic factors & Cytke & ve cases & Cytk & $0+$ ve cases \\
\hline $\begin{array}{ll}\text { Bilharzial infestation of UC: } \\
\text { Negative } & (\mathrm{n}=80) \\
\text { Positive } & (\mathrm{n}=70)\end{array}$ & $\begin{array}{c}\text { No. } \\
64 \\
56\end{array}$ & $\begin{array}{l}\%) \\
(80 \%) \\
(80 \%)\end{array}$ & $\begin{array}{c}\text { No. } \\
58 \\
49\end{array}$ & $\begin{array}{l}(\%) \\
(72.5 \%) \\
(60 \%)\end{array}$ \\
\hline $\begin{array}{ll}\text { Tumor Type: } & \\
\text { SCC } & (\mathrm{n}=50) \\
\text { UC } & (\mathrm{n}=150)\end{array}$ & $\begin{array}{c}0 \\
120\end{array}$ & $\begin{array}{c}(0 \%)^{\mathrm{c}} \\
(80 \%)^{\mathrm{c}}\end{array}$ & $\begin{array}{c}0 \\
105\end{array}$ & $\begin{array}{r}(0 \%) \\
(70 \%)^{\mathrm{a}}\end{array}$ \\
\hline $\begin{array}{l}\text { Histopathological stage of UC: } \\
\quad T_{a}(n=10) \\
T_{1}(n=60) \\
\text { Invasive }\left[T_{2}+T_{3}\right] \quad(n=80)\end{array}$ & $\begin{array}{c}2 \\
38 \\
80\end{array}$ & $\begin{array}{l}(20.8 \%) \\
(47.5 \%)^{b} \\
(100 \%)^{b c}\end{array}$ & $\begin{array}{l}15 \\
50 \\
40\end{array}$ & $\begin{array}{l}(100 \%) \\
(83.3 \%)^{\mathrm{b}} \\
(50 \%)^{\mathrm{bc}}\end{array}$ \\
\hline $\begin{array}{ll}\text { Histopathological grade of UC: } \\
\text { G I } & (\mathrm{n}=20) \\
\text { G II } & (\mathrm{n}=40) \\
\text { G III } & (\mathrm{n}=90)\end{array}$ & $\begin{array}{c}4 \\
26 \\
90\end{array}$ & $\begin{array}{l}(20 \%) \\
(65 \%)^{d} \\
(100 \%)^{\text {de }}\end{array}$ & $\begin{array}{l}20 \\
35 \\
50\end{array}$ & $\begin{array}{l}(100 \%) \\
(87.5 \%)^{d} \\
(68.6 \%)^{d e}\end{array}$ \\
\hline
\end{tabular}

\section{Explanation of Figure}

Fig. 1(A-D): A) Case of papillary UC, low grade, T1 associated with schistosomiasis showed marked expression of cytokeratin 20 as cytoplasmic brownish stain (IHC,DAB,x40,x200), B): A case of UC high grade, T2 showed mild expression of cytokeratin 20 (IHC, DAB, x40, 200), C) A UC high grade, $\mathrm{T} 2$ associated with schistosomiasis (small red arrow point to bilharzial ova) showed high expression of marked expression of cytokeratin 7 as brownish cytoplasmic stain (IHC, DAB, x40, x200), D) A Case of UC, high grade, T1 associated with schistosomiasis showed focal expression of cytokeratin 14 as cytoplasmic brownish stain in areas with squamoud differentiation (IHC,DAB,x40,x200). 

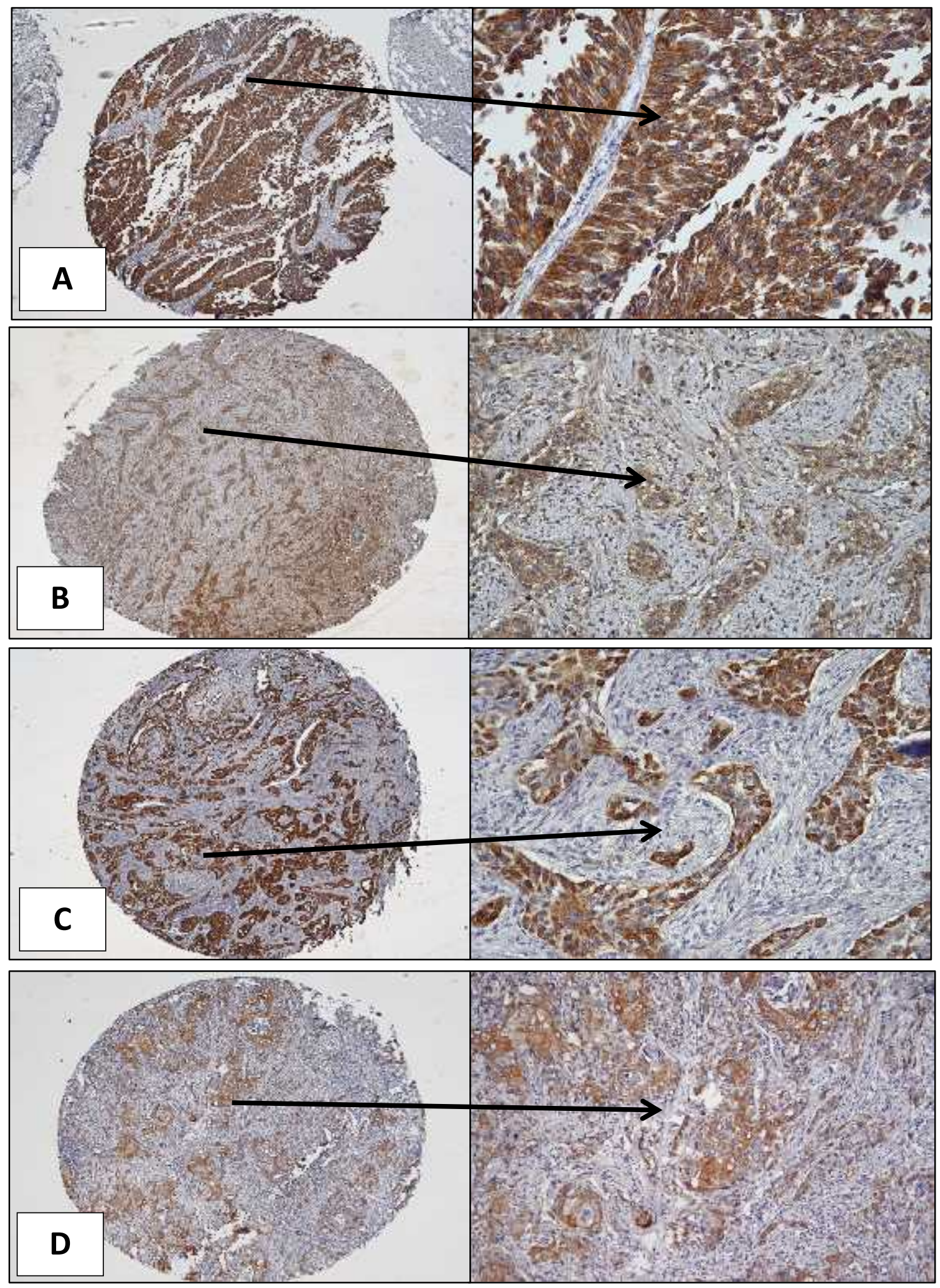